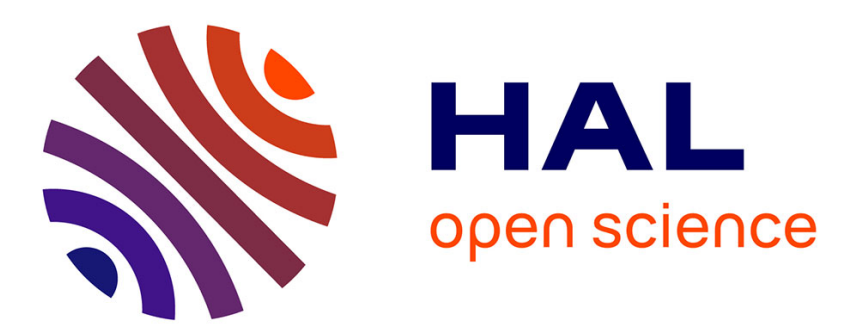

\title{
The full life cycle of Leptosphaeria maculans completed on inoculated oilseed rape incubated under controlled conditions
}

\author{
Lydia Bousset, Magali Ermel, Lionel Lebreton
}

\section{- To cite this version:}

Lydia Bousset, Magali Ermel, Lionel Lebreton. The full life cycle of Leptosphaeria maculans completed on inoculated oilseed rape incubated under controlled conditions. Plant Pathology, 2018, 67 (6), pp.1321-1328. 10.1111/ppa.12853 . hal-02622715

\section{HAL Id: hal-02622715 \\ https://hal.inrae.fr/hal-02622715}

Submitted on 26 May 2020

HAL is a multi-disciplinary open access archive for the deposit and dissemination of scientific research documents, whether they are published or not. The documents may come from teaching and research institutions in France or abroad, or from public or private research centers.
L'archive ouverte pluridisciplinaire $\mathbf{H A L}$, est destinée au dépôt et à la diffusion de documents scientifiques de niveau recherche, publiés ou non, émanant des établissements d'enseignement et de recherche français ou étrangers, des laboratoires publics ou privés.

$$
\text { Copyright }
$$




\title{
The full life cycle of Leptosphaeria maculans completed on inoculated oilseed rape incubated under controlled conditions
}

\author{
L. Bousset, M. Ermel, L. Lebreton
}

\section{INRA, UMR1349 IGEPP, Le Rheu F-35653, France}

\begin{abstract}
Because epidemics of successive cropping seasons are not independent, epidemiological studies need to encompass the processes occurring during the transmission of epidemics from one season to the next. With Leptosphaeria maculans, infected stubble allows carry-over of the fungus. Generation experiments using recurrent selection on field plots are a useful means of comparing the effects of selection pressures. However, the full life cycle of the fungus, from plant infection to the next generation of ascospores, has not yet been achieved under controlled conditions. Studies were undertaken to achieve an experimental set-up with sexual reproduction under controlled conditions. Cankered oilseed rape stems were produced under controlled conditions, after inoculation with a mixture of 12 isolates across both mating types. Stems were cut longitudinally and attached to styropore plates. Stem halves were incubated outside or in climate chambers regularly soaked in tap water to ensure maturation. Incubation was stopped when mature pseudothecia were observed. In all three independent experiments, more stem halves had pseudothecia when incubated under controlled conditions (30-100\%) than incubated outside (0-80\%). To the authors' knowledge, this is the first study achieving the full life cycle of the fungus under controlled conditions, from infection of the plant to mature pseudothecia. This opens up the prospect of running experiments year-round to better understand inoculum production, to compare fungal fitness, or to run generation experiments with exotic pathogen populations.
\end{abstract}

Keywords: epidemiology, generation experiments, phoma stem canker, pseudothecia, sexual reproduction

\section{Introduction}

In agro-ecosystems, human actions result in alternate continuities and discontinuities over time and space, for example for the presence versus absence of host crops, and this induces cyclic epidemics (Bousset \& Chèvre, 2013). Thus, the adaptation of pathogen populations to host resistances has to be studied at the scale of a network of fields on which the selection pressures are not homogeneous, over a succession of cropping seasons (Bousset \& Chèvre, 2013). Because epidemics of successive cropping seasons are not independent, epidemiological studies need to encompass the processes occurring during the transmission of epidemics from one season to the next. Phoma stem canker of oilseed rape is one of the few pathosystems for which such data are becoming available.

Leptosphaeria maculans is one of the causes of stem canker (Shoemaker \& Brun, 2001). In Europe, phoma stem canker is considered a monocyclic disease (West et al., 2001). Epidemics are initiated in autumn, leaf spots are observed from autumn to early spring and stem cankers develop from spring to summer, up to the time of harvest. Unlike the situation in Canada and Australia (Barbetti, 1976; Hall et al., 1996), secondary cycles of infection by means of conidia produced on leaf spots have not been documented in Europe. Cankers develop due to the systemic growth of fungal hyphae from leaf spots to the leaf petiole through xylem vessels, and subsequently to the stem base (Hammond et al., 1985; Travadon et al., 2009). The fungus can survive as hyphae in crop stubble, forming two kinds of fruiting bodies: pycnidia and pseudothecia. Pseudothecia can only be formed by sexual reproduction if isolates of opposite mating types co-occur in the same oilseed rape stem. Spores produced in asexual pycnidia and pseudothecia are, respectively, conidia (pycnidiospores) passively rain splashed short distances, and ascospores actively ejected and wind dispersed (Marcroft et al., 2004; Savage et al., 2013; Bousset et al., 2015). The dispersal kernel of L. maculans ascospores from stubble left after harvest in the summer prior to newly sown oilseed rape fields was estimated using phoma stem canker autumn disease severity (Bousset et al., 2015). Infected stubble ensures the carry-over of the fungus 
from one season to the next (Marcroft et al., 2004; Lô-Pelzer et al., 2009; L. Bousset unpublished results), and serves as the main source of inoculum.

Disease control relies on the use of resistance genes in varieties. However, when resistance genes have been deployed in oilseed rape varieties, phoma stem canker populations have repeatedly become adapted over a few years. Documented examples are adaptation to the genes Rlm1 in Europe and Australia (Rouxel et al., 2001; Van de Wouw et al., 2017), Rlm1 and LepR1 in Australia (Van de Wouw et al., 2017), Rlm7 in Europe (Winter \& Koopmann, 2016) and Rlm3 in Canada (Zhang et al., 2016). Modelling studies aim to understand adaptation of fungal populations depending on the deployment of host varieties (Lô-Pelzer et al., 2010). The yearly occurrence of sexual reproduction contributes to the adaptive potential of the fungus (McDonald \& Linde, 2002). Indeed, at each sexual generation, repeat-induced point (RIP) mutations promote the appearance of new alleles with the loss of avirulence genes (Rouxel et al., 2011). Thus, further studies including sexual reproduction are required to understand adaptation dynamics, for example to identify how the fungus can combine avirulence genes under contrasting selection pressures.

Generation experiments using recurrent selection on field plots are a useful means of comparing the effects of selection pressures on phoma stem canker populations (Brun et al., 2010; Delourme et al., 2014). Over a succession of cropping seasons, when harvested stubble is matured outside over summer and then used to inoculate field plots, fungal population dynamics during the adaptation to host resistance with contrasting selection pressures can be studied. This protocol has recently been extended to the combination of stubble sources and variation in the amount of inoculum used (Bousset et al., 2018). However, the use of field plots for generation experiments is restricted to local populations. Because phoma stem canker populations are diversified worldwide, with contrasting histories regarding the use of plant resistance genes and subsequent adaptation of pathogen populations, achieving the capacity to run generation experiments under controlled conditions would greatly expand the ability to study and understand adaptation dynamics. Specifically, when resistance genes are still locally efficient but exotic populations already adapted exist elsewhere, one cannot perform field experiments, but could work in confined environments.

The aim of this study was to create an experimental set-up for achieving a full life cycle of $L$. maculans under controlled conditions. Generation experiments under controlled conditions (Fisher \& Lang, 2016) are common for fungi with asexual generations, e.g. for cereal rusts (Kolmer, 1993) or powdery mildews (Bousset \& Pons-Kühnemann, 2003). However, because of the major impact of sexual reproduction on the appearance of new alleles, generation experiments with phoma stem canker should include sexual reproduction. Leptosphaeria maculans has been successfully crossed on artificial media for species identification (Shoemaker \& Brun, 2001), genetics of the interaction and production of ascospores (Huang et al., 2003). On stubble collected from fields, the incubation process started outside has been completed under controlled conditions, enabling studies on the effect of climate on maturation (Huang et al., 2003; Toscano-Underwood et al., 2003; Naseri et al., 2009). In addition, infection, the systemic pathway and cankers can be obtained under controlled conditions (Huang et al., 2009; Travadon et al., 2009). However, achieving the full life cycle of the fungus, from plant infection to sexual reproduction of the next generation of ascospores, has not yet been achieved under climate-controlled conditions.

\section{Materials and methods}

\section{Fungus}

Twelve isolates of L. maculans from the study of Gout et al. (2006) were used. These were single-pycnidia isolates obtained from leaf lesions collected from three oilseed rape fields in France as soon as the first leaf lesions were observed in Le Rheu (western France), Oucques (central France), and Grignon (near Paris) in autumn 2000 (Table 1). Although the current study does not take advantage of it, the main criterion for choosing the isolates was to have distinct minisatellite alleles at two loci, making it possible to identify the presence of each of them even when co-occurring in the same stem (authors' unpublished data). The second criterion was to allow for sexual crosses between the isolates, thus having the two mating types represented. As the choice was limited by the minisatellite alleles, a 50:50 ratio could not be achieved, and of the 12, three had the MAT1-2 and nine had the MAT1-1 mating type alleles (Cozijnsen \& Howlett, 2003). Inoculum, consisting of suspensions of $10^{7}$ pycnidiospores per $\mathrm{mL}$, was obtained as described by De March et al. (1986) 
for each isolate. The 12 inocula were then combined in equal amounts, for a final concentration of $8.33 \times 10^{5}$ pycnidiospores of each isolate per $\mathrm{mL}$.

Table 1. Origin and mating type allele of the 12 Leptosphaeria maculans isolates used in this study

\begin{tabular}{lll}
\hline Isolate & Origin & Mating type \\
\hline 1 & Grignon & MAT1-1 \\
2 & Grignon & MAT1-1 \\
3 & Grignon & MAT1-1 \\
4 & Grignon & MAT1-2 \\
5 & Le Rheu & MAT1-2 \\
6 & Le Rheu & MAT1-1 \\
7 & Oucques & MAT1-1 \\
8 & Oucques & MAT1-1 \\
9 & Oucques & MAT1-1 \\
10 & Oucques & MAT1-1 \\
11 & Oucques & MAT1-1 \\
12 & Oucques & MAT1-2 \\
\hline
\end{tabular}

Isolates were sampled in autumn 2000 in Grignon (near Paris), Le Rheu (western France) and Oucques (central France) in a study by Gout et al. (2006).

Plants, inoculation and disease assessment

Three replicate experiments were carried out, with inoculated plants prepared just before the start of the incubation in summer, autumn and winter 2014 for Experiments 1-3, respectively (Table 2). After pregermination on wet filter paper, seeds of the susceptible oilseed rape cultivar Bristol were transplanted in $9 \times 9 \mathrm{~cm}$ pots with a 1:1:1 mix of sand, peat and compost and grown under a $16 \mathrm{~h}$ photoperiod for 20-23 days. Growth chamber temperatures were $18{ }^{\circ} \mathrm{C}$ night $/ 20^{\circ} \mathrm{C}$ day for Experiments 1 and 2 , and $15{ }^{\circ} \mathrm{C}$ night $/ 18{ }^{\circ} \mathrm{C}$ day for Experiment 3.

Table 2. Timetables for the three independent experiments performed, and results for the nine sets of stem halves

\begin{tabular}{|c|c|c|c|c|c|c|c|c|c|}
\hline Experiment & \multicolumn{3}{|l|}{ Exp. 1} & \multicolumn{3}{|l|}{ Exp. 2} & \multicolumn{3}{|l|}{ Exp. 3} \\
\hline \multicolumn{10}{|l|}{ Timetable } \\
\hline Sowing & \multicolumn{3}{|l|}{ 2014-03-18 } & \multicolumn{3}{|l|}{ 2014-09-23 } & \multicolumn{3}{|l|}{ 2014-11-24 } \\
\hline Inoculation & \multicolumn{3}{|l|}{ 2014-04-10 } & \multicolumn{3}{|l|}{$2014-10-13$} & \multicolumn{3}{|c|}{ 2014-12-15 } \\
\hline Canker assessment & \multicolumn{3}{|l|}{$2014-05-27$} & \multicolumn{3}{|l|}{$2014-11-24$} & \multicolumn{3}{|c|}{$2015-01-27$} \\
\hline End of incubation & \multicolumn{3}{|c|}{ 2014-10-16 } & \multicolumn{3}{|c|}{$2015-04-03$} & \multicolumn{3}{|c|}{$2015-07-27$} \\
\hline $\begin{array}{l}\text { Fruiting bodies on each set of stems } \\
\text { Inoculated stem halves }\end{array}$ & Out & $\mathrm{SCa}$ & $\mathrm{SCb}$ & Out & $\mathrm{SC}$ & $\mathrm{CC}$ & Out & SC & $\mathrm{CC}$ \\
\hline Number & 24 & 48 & 48 & 10 & 43 & 43 & 10 & 49 & 49 \\
\hline Mean canker length (SE) & $31.2(3.5)$ & $24.1(1.9)$ & $24.1(1.9)$ & $19.4(4.6)$ & $28.5(1.6)$ & $28.4(1.7)$ & $26.8(3.7)$ & $23.6(2.0)$ & $24.2(2.0)$ \\
\hline No. with pseudothecia & 9 & 48 & 45 & 0 & 18 & 25 & 8 & 40 & 46 \\
\hline Proportion with pseudothecia & 0.39 & 1.00 & 0.96 & 0.00 & 0.42 & 0.58 & 0.80 & 0.82 & 0.94 \\
\hline \multicolumn{10}{|l|}{ Mock-inoculated stem halves } \\
\hline No. stem halves & 4 & 6 & 6 & 4 & 5 & 5 & 4 & 5 & 5 \\
\hline Mean canker length & 0 & 0 & 0 & 0 & 0 & 0 & 0 & 0 & 0 \\
\hline No. with pseudothecia & 0 & 0 & 0 & 0 & 0 & 0 & 0 & 0 & 0 \\
\hline
\end{tabular}

Incubations were performed outside (Out) or inside with temperature semicontrolled ( $\mathrm{SC}, \mathrm{SCa}, \mathrm{SCb})$ or fully regulated (CC). Number of stem halves (Number), mean canker length (in $\mathrm{mm}$ ) at the start of incubation with standard errors of the means (SE), numbers and proportions of stem halves with pseudothecia at final inspection are indicated for each set. SCa and $\mathrm{SCb}$ are two sets of stems in the same room.

The petiole of the second leaf was cut off $0.5 \mathrm{~cm}$ from the stem and a $10 \mu \mathrm{L}$ drop of a pycnidiospore suspension $\left(10^{7}\right.$ pycnidiospores per $\left.\mathrm{mL}\right)$ was deposited on the wound of 60,48 and 54 plants in Experiments $1-3$, respectively. Plants treated with distilled water instead of spore suspension served as controls, with 8,7 and 7 plants in Experiments 1-3, respectively. A plastic cover was placed over the inoculated plants to create a $100 \%$ relative humidity $(\mathrm{RH})$ atmosphere for $48 \mathrm{~h}$, in the dark for the first $24 \mathrm{~h}$. Forty-two days after 
inoculation, stems were cut longitudinally. Disease severity was assessed as the length of internal canker on each half of the stem (Fig. 1).

Figure 1 Illustrations of the inoculation process. (a) Plant with external canker before scoring. (b) Stems cut longitudinally for canker length assessment, then pinned to styropore plates along their entire length for controlled conditions (top) or only at the edges for outside incubation (bottom). (c) Styropore plates floating on water during soaking. (d) Stem halves after incubation under controlled conditions. (e) Stem halves after incubation outside on soil. $(f, g, h)$ Close-ups of pseudothecia after incubation. Pictures were taken in colour and then converted to black and white, with sharpness brightness and contrast increased by $20 \%$.
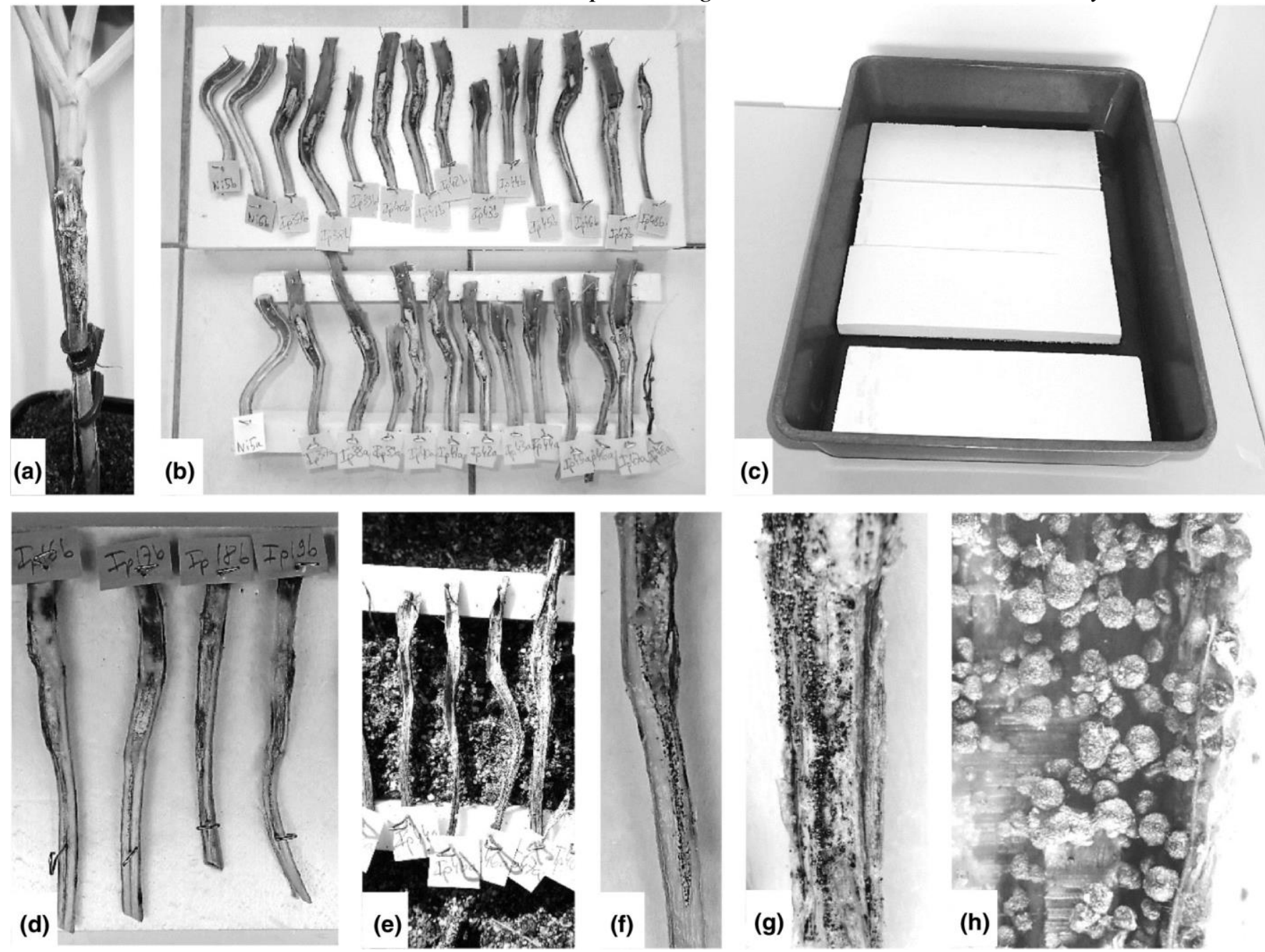

\section{Stem fragment incubation}

The three experiments were performed at three different times of year to obtain different incubation conditions on the cankered stems, and under three incubation set-ups: outside (Out), in a semicontrolled room (SC), or in a fully controlled growth chamber (CC; Table 2). Within each of the three experiments, the two halves of a given stem were always attributed to different incubation sets within the experiment. This made an overall total of nine sets of half-stems, with always one outside (Out) and two inside for a total of 120 (16), 96 (14) and 108 (14) inoculated (control) half-stems in Experiments 1, 2 and 3, respectively (Table 2). Experiment 1 had two sets in semicontrolled conditions ( $\mathrm{SCa}$ and $\mathrm{SCb}$ ), whereas Experiments 2 and 3 had one set in semicontrolled conditions (SC) and one set in controlled conditions (CC).

Outside incubation was located at INRA Le Rheu $\left(48.1^{\circ} \mathrm{N}, 1.5^{\circ} \mathrm{W}\right)$, in Brittany, France. Stem halves were placed in trays on a 1:1:1 mix of sand, peat and compost, with the outer side of the stem touching the soil. Moisture and temperature depended on the local climate and natural rain only. In this area, winter oilseed rape is generally sown in late August-September and harvested the following July. Experiment 2 therefore corresponded to the period when stubble in farmers' fields is maturating. 
Inside incubation was performed either under controlled (CC) or semicontrolled (SC) conditions. Controlled conditions were in a fully regulated growth chamber with a $16 \mathrm{~h}$ photoperiod and temperatures of $18{ }^{\circ} \mathrm{C}$ night $/ 20{ }^{\circ} \mathrm{C}$ day. Semicontrolled conditions were in a room where the temperature was set at $20{ }^{\circ} \mathrm{C}$ day, but varied depending on the outside temperature, with heating ensured by the $16 \mathrm{~h}$ photoperiod neon light. In both cases, neon tubes were OSRAM L36W/865 Lumilux Cool Daylight. Stem halves were attached to styropore plates using pins, the outer side of the half-stem touching the plate (Fig. 1b). From then on, the half-stems always remained within their given CC or SC environment, undergoing alternate wet (soaking) and dry periods. Plates were laid in trays with stems facing up (therefore receiving light) most of the time. Twice per week, tap water (i.e. drinking water including chloride; values published by the local water agency were $0.7 \mathrm{mg} \mathrm{L}^{-1} \mathrm{Cl}_{2}$ in a sample of 17 November 2014) was poured in the tray and plates were flipped, floating on the water with stems immersed (Fig. 1b). Soaking duration was recorded and cumulative wetting time was computed over the experiment (Fig. 2). At the end of the soaking period, water was poured out and the styropore plates were flipped again, with stems facing upwards, and slowly dried out over the following days.

Figure 2 Temperatures $(a, b)$ and rain $(c)$ or soaking $(d)$ duration for the incubation either outside $(a, c)$ or under controlled conditions $(b, d)$ for the three independent experiments. Inside, temperature was either semicontrolled (SC) or fully regulated $(C C)$. Daily mean temperatures $\left({ }^{\circ} \mathrm{C}\right)$, daily rainfall outside (hours) or daily soaking time under controlled conditions (hours) were cumulated over the duration of the experiments.

(a) Temperatures outside

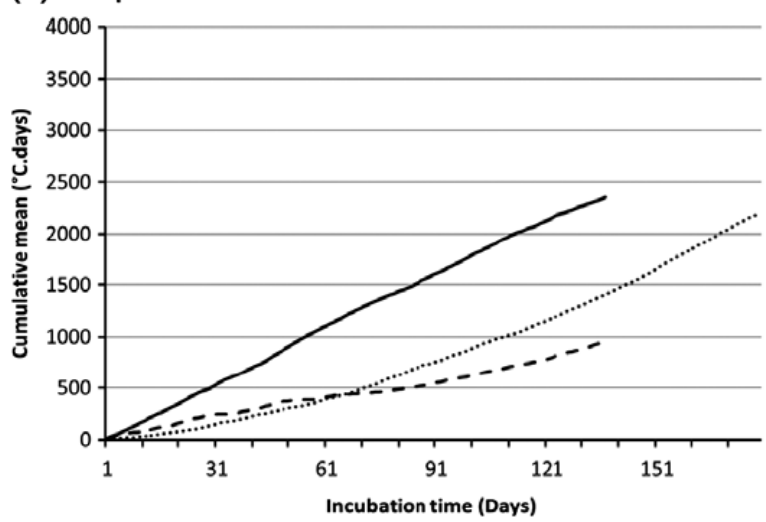

(c) Rain outside

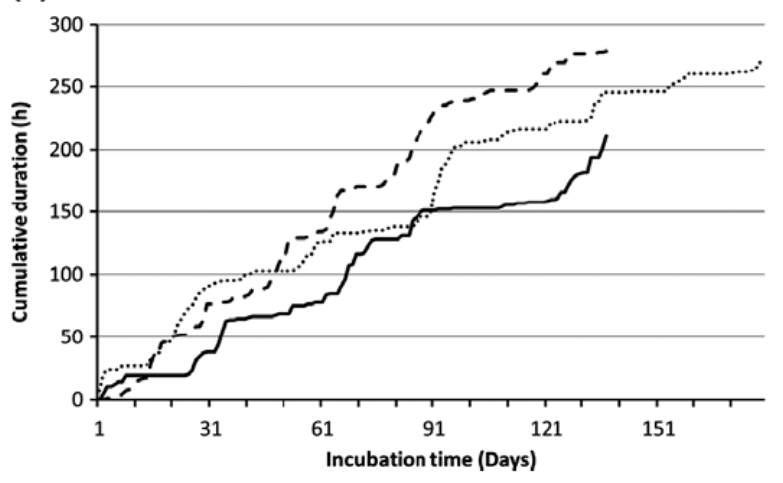

(b) Temperatures inside

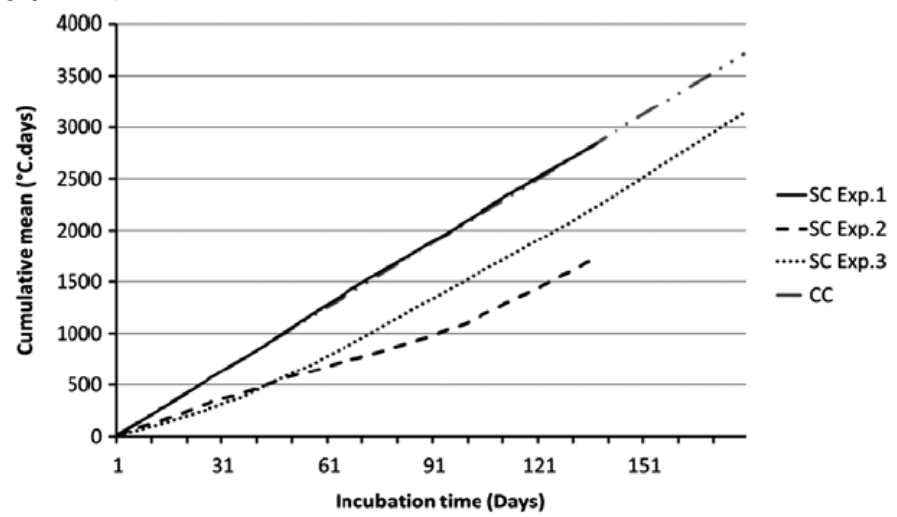

(d) Soaking time inside

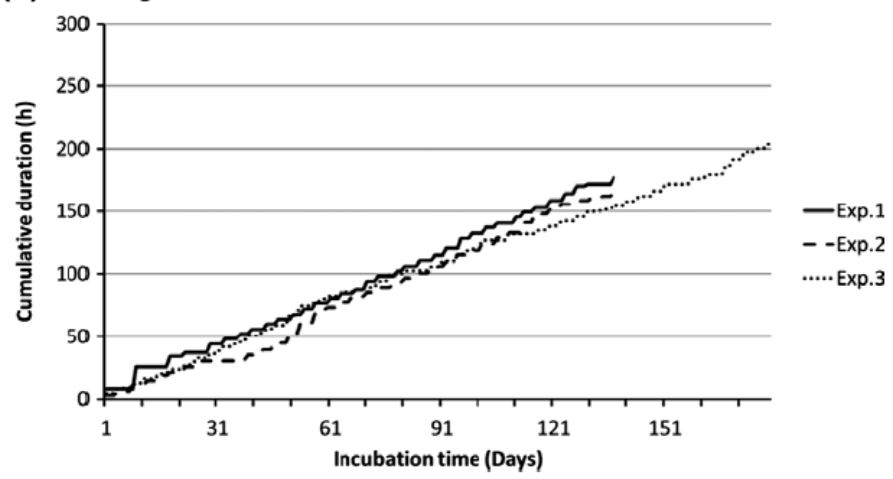

Assessment of fruiting bodies

Rapid visual inspection was made every fortnight outside, and after each soaking event inside, surveying the presence of small fruiting bodies (pycnidia) and later on, of larger fruiting bodies (pseudothecia). When large fruiting bodies were detected, some of the stem halves were observed under the magnifying binocular lenses to confirm the presence of the typical ostiole. If confirmed, the contents of some of the largest fruiting bodies were observed under the microscope. Incubation was stopped simultaneously for all stem halves of the experiment when fruiting bodies containing typical L. maculans asci with differentiated ascospores were observed (Table 2). Styropores plates were dried and stored at room temperature until the final inspection.

The final inspection of pseudothecia incidence was made on 24 July 2015, after incubation was completed for the three experiments. All the styropore plates were soaked for a few minutes before inspection. The presence 
of fruiting bodies was recorded after inspection under the magnifying binocular lenses. For each of the stem halves, two to four of the largest fruiting bodies were transferred onto a drop of water and crushed for observation under the microscope. The stem half was classified in one of two categories, either without or with pseudothecia. The first category encompassed half-stems with either no fruiting bodies, only pycnidia (fruiting bodies containing numerous small conidia) or with a content not corresponding to L. maculans (shape of the asci or shape of the spores). The second category encompassed half-stems bearing either large fruiting bodies with typical ostioles and differentiated pseudoparaphysoid tissue (immature pseudothecia) or fruiting bodies with typical differentiated asci, all the way to differentiated ascospores.

\section{Climatic data}

The climate in the area is oceanic, and meteorological data were obtained from the INRA CLIMATIK database, for Le Rheu weather station. For the outside incubation, the amount of rain $(\mathrm{mm})$ on an hourly basis was used to sum up the number of hours with rain for each day, and then to calculate cumulative hours with rain over the course of each experiment. For the inside incubation, cumulative hours of soaking over the course of each experiment were calculated using the recorded starting/ending times of each soaking event.

Cumulative temperatures over the course of each experiment were calculated using mean daily temperature from the CLIMATIK database for the outside incubation (Out), and daily mean of hourly temperatures recorded with an OCEASOFT button in the controlled condition (CC) fully regulated growth chamber. For the semicontrolled (SC) room, hourly temperature records were available for three periods (2014-06-01 to 2014-08-08; 2015-01-17 to 2015-04-10; 2015-05-22 to 2015-07-31). For the remaining time, records were lost due to a device defect, and the inside temperature was reconstructed from the available outside data. Because the room was only semicontrolled, the inside temperature depended on the setting (set at $20{ }^{\circ} \mathrm{C}$ day) but as the room was poorly isolated, the achieved temperature was lower than the setting when the outside temperature was below this. The higher the outside temperature, the smaller the difference between inside and outside temperatures. Significance of the correlation was tested assuming a linear model with the inside temperature dependent on the outside temperature and the normal versus cold periods. Correlation was highly significant (adjusted $R^{2}=0.97, F=2014$ on 3 and 149 d.f., $P<2.2 \mathrm{e}^{-16}$ ). As all outside temperature data was available and the correlation was highly significant, the estimated parameters of the linear correlation were used to compute the reconstructed inside temperature data from the available outside data.

\section{Statistical analysis}

Statistical analyses were performed using R software (R Core Team, 2013). The length of internal cankers from the nine sets of stems were compared using a linear model [LM; function lm, package lme4 (Bates, 2010)]. Pairwise comparisons of least squares means (lsmeans) were performed using the function lsmeans (package lsmeans; Lenth, 2016) and the false discovery rate correction (FDR) for $P$-values (Benjamini \& Hochberg, 1995).

At the end of the incubation period, the proportion of stems with versus without pseudothecia were compared using Fisher's exact test. Due to multiple pairwise comparisons, $P$-values were converted into false discovery rate (FDR) values. The following effects were tested: incubation conditions (outside, semicontrolled, fully controlled); time of experiment (summer, autumn, winter) whatever the incubation conditions; and time of experiment among stems incubated inside.

\section{Results}

Homogeneity of disease severity among the nine sets of stem halves

In all three experiments, no cankers were observed on the 22 mock-inoculated control stems. Cankers of variable length were obtained on individual inoculated stems (Fig. 1; Table 2) with mean canker length from 21.6 to $31.2 \mathrm{~mm}$. However, overall mean canker length was not significantly different among the nine sets $(F=1.69$; d.f. $=8 ; P=0.10)$. None of the pairwise lsmeans comparisons were significant, indicating that the nine sets of half stems were homogeneous for disease severity. 
Incubation temperatures and rain or soaking duration

Experiments 1, 2 and 3 were run for 143, 131 and 182 days, respectively (Table 2; Fig. 2). Over these periods, mean temperature was highest in the controlled conditions growth chamber $\left(20.8^{\circ} \mathrm{C}\right)$, intermediate in the semicontrolled one $\left(20.7,12.7,17.5^{\circ} \mathrm{C}\right)$ and lowest outside $\left(17.2,7.0\right.$ and $\left.12.3^{\circ} \mathrm{C}\right)$ over the three experiments, respectively. Nevertheless, cumulative temperatures remained of the same order of magnitude inside in the controlled (N/A, 2843, 3714 degree-days) and semicontrolled (2834, 1734 and 3133 degree-days) chambers and outside (2356, 961 and 2203 degree-days).

Cumulative rainfall outside was 289,274 and $314 \mathrm{~mm}$ over a duration of 211, 279 and $270 \mathrm{~h}$ for the three experiments, which is of the same order of magnitude as the cumulative soaking time inside $(177,167$, $205 \mathrm{~h})$.

\section{Proportion of half stems bearing fruiting bodies at final inspection}

No pseudothecia were observed on any of the 44 mock-inoculated stem halves, so the analyses were focused on the inoculated stems. Fewer stem halves with pseudothecia were observed when incubated outside, compared to climate chambers (Fisher's exact test; $P=2.8 \mathrm{e}^{-9}$; Table 2 ). In contrast, $42-100 \%$ of stem halves incubated in controlled conditions had pseudothecia. Proportions were lower in Experiment 2 than in Experiments 1 and 3 (Fisher's exact test; $P=1.4 \mathrm{e}^{-14}$ ). There was no difference between SC and CC (Fisher's exact test; $P=0.43$ ). Inside, fewer stem halves had pseudothecia in Experiment 2 than in Experiment 1 (Fisher's exact test; $P=9.8 \mathrm{e}^{-15}$ ) or in Experiment 3 (Fisher's exact test; $P=2.2 \mathrm{e}^{-8}$ ).

\section{Discussion}

Ascospores produced by sexual reproduction are the main source of inoculum for L. maculans epidemics (West et al., 2001). Fruiting body formation, maturation and spore release depend on temperature and humidity (West et al., 2001; Naseri et al., 2009). A number of previous studies have focused on understanding and forecasting the timing of fruiting body maturation and ascospore release (Savage et al., 2013; Brachaczek et al., 2016). Release of ascospores from stubble under controlled conditions was achieved when stubble maturation was started outside (Huang et al., 2003; Naseri et al., 2009; McCredden et al., 2018). But to the authors' knowledge, this study is the first achieving the full life cycle of the fungus on plant tissues produced and inoculated inside, from plant infection to sexual reproduction of the next generation of ascospores under climate controlled conditions.

Stems bearing mature pseudothecia were obtained following incubation inside, with either controlled or semicontrolled temperatures. Critically, pseudothecia were obtained in all three experiments, whatever the season, whereas outside incubation failed in autumn 2014 when cumulative temperature was lower. Maturation of the fungus thus can be achieved on tissues younger than those observed in the field; however, follow-up studies are required to optimize the incubation conditions. Specifically, incubation took longer inside in Experiment 2 than Experiments 1 and 3. There was no difference between SC and CC, thus climate could not be the explanation. Also, even if plants were inoculated at different times, there was no difference in canker length. The only difference between experiments was the lower temperature during the production of infected plants in Experiment 2 and the fact that they were assessed slightly earlier. In Poland, the maturing, but still moist and living stems influences the earlier and more abundant formation of pseudothecia with ascospores of Leptosphaeria species (Dawidziuk et al., 2012). The present study opens up the prospect of running experiments year-round, but the influence of plant age and conditions of inoculation deserve further study.

The overall incubation process took 131 to 182 days, allowing for two to three generations per year, plus 60-70 days from sowing to produce the stems with canker. Both temperature and humidity affect the incubation time (Naseri et al., 2009). Favourable temperature range is quite broad, restricted only by very cold temperatures below $2{ }^{\circ} \mathrm{C}$ e.g. in Canada, or high temperatures above $22{ }^{\circ} \mathrm{C}$ e.g. in Western Australia (Salam et al., 2003). Maturation requires high humidity as increased delay between simulated rains delays maturation (Salam et al., 2003), and conversely continuous wetness shortens maturation time (Naseri et al., 2009). The present study is congruent with these results, with the longest maturation period in Experiment 2 outside, when the temperature was lowest. There were no differences between semicontrolled and fully controlled climate conditions, nor between seasons inside, indicating that continuous conditions are as suitable as more flexible 
ones. Follow-up studies could aim to reduce the total length of the experiment. Marginally, because tap water was used inside and rain water outside, and more stems with pseudothecia were obtained inside, it cannot be excluded that chlorine affected fungal maturation, as many chemicals do interfere with this process (Wherrett et al., 2003).

In this experiment, incidence of pseudothecia was recorded, because the aim was to investigate whether mature pseudothecia could be obtained. Detailed characterization of severity, e.g. numbers or densities of pseudothecia by counts under the microscope (Lô-Pelzer et al., 2009; Naseri et al., 2009) or picture processing (L. Bousset, unpublished results) could provide a more accurate understanding of the processes in further studies.

Quantitative resistance reduces disease severity, measured by canker length (Delourme et al., 2006; Travadon et al., 2009) and mycelial systemic growth (Huang et al., 2009). Competition effects during systemic growth have been detected (Travadon et al., 2009), as the canker severity in coinfected plants differed from the severity achieved by the same isolates inoculated alone. So far, fitness of isolates has been compared among isolates grown on media or as disease symptom size on young plants (Huang et al., 2006). Because the present study achieved maturation of cankered stems produced inside, it opens up the prospect of measuring fitness of isolates at both early and later stages in the fungal life cycle, from comparing either the fitness for sexual reproduction, or the amount of inoculum produced which can be transmitted to the next generation. Until now, this has been seldom possible for fungi (Tollenaere \& Laine, 2013; Suffert et al., 2016).

Understanding inoculum production at the end of the epidemic is critical to the development of disease control strategies at the landscape scale, for example with the assistance of pluriannual simulators (Lô-Pelzer et al., 2010). Dynamics of inoculum production has been related to climate (Huang et al., 2003; Naseri et al., 2009; Savage et al., 2013; Brachaczek et al., 2016; McCredden et al., 2018), to canker severity (Lô-Pelzer et al., 2009), to chemical treatments (Wherrett et al., 2003), and to host genotypes (McCredden et al., 2018). The present set-up opens up the prospect of further studies on the dynamics of inoculum production depending on e.g. host genotype, nitrogen availability, competition with microbes or chemical treatment.

Improving disease control strategies using the plant resistance in varieties requires a better understanding of the dynamics of adaptive change in variable L. maculans populations exposed to different selective pressures (host resistance genes). Previous field studies involved a single pathogen population exposed to different hosts (Brun et al., 2010; Delourme et al., 2014), to contrasting stubble management practices (Daverdin et al., 2012), or to a combination of stubble sources, resistance genes in the host and inoculum loads (Bousset et al., 2018). On the one hand, the outcome of these studies was largely driven by which resistance gene the pathogen population had been exposed to. Pathogen evolutionary trajectories (i.e. responses to selection pressure) are at least partly determined by the genetic composition of the initial pathogen population. However, field studies can only be performed with local pathogen populations. As L. maculans populations are contrasted worldwide, performing generation experiments under controlled conditions (Fisher \& Lang, 2016) would circumvent this limitation. This study indicates that such generation experiments are possible. Specifically, follow-up studies with one isolate of each mating type could confirm if the set-up works with only two isolates. If so, it would become possible to generate and understand the accumulation of pathogen virulence. Sexual crosses in vitro are already possible (Shoemaker \& Brun, 2001; Huang et al., 2003) but performing specific crosses under the selective pressure of the plant genetic background would allow insights into adaptation, as well as generating pathogen strains useful for the identification of resistance genes in plant varieties.

\section{Acknowledgements}

The authors thank the editor and three anonymous reviewers for their suggestions to greatly improve the manuscript. They thank Lydie Kerdraon, Ronan Le Cointe and Anne Levrel for technical assistance, the BraCySol Biological Resource Center for providing oilseed rape seeds, and Lilian Gout and Mylène Balesdent for providing the L. maculans isolates. This work benefited from the financial support of INRA - the French National Institute for Agronomical Research. The authors declare no conflict of interest. 


\section{References}

Barbetti MJ, 1976. The role of pycniospores of Leptosphaeria maculans in the spread of blackleg disease in rape. Australian Journal of Experimental Agriculture and Animal Husbandry 16, 911-4.

Bates D, 2010. lme4: Mixed-effects modeling with R. [http://lme4.r-forge.r-project.org]. Accessed 27 February 2018.

Benjamini Y, Hochberg Y, 1995. Controlling the false discovery rate: a practical and powerful approach to multiple testing. Journal of the Royal Statistical Society B 57, 289-30.

Bousset L, Chèvre AM, 2013. Stable epidemic control in crops based on evolutionary principles: adjusting the metapopulation concept to agro-ecosystems. Agriculture, Ecosystems \& Environment 165, 118 29.

Bousset L, Pons-Kühnemann J, 2003. Effects of acibenzolar-S-methyl and ethirimol on the composition of a laboratory population of barley powdery mildew. Phytopathology 93, 305-15.

Bousset L, Jumel S, Garreta V, Picault H, Soubeyrand S, 2015. Transmission of Leptosphaeria maculans from a cropping season to the following one. Annals of Applied Biology 166, 530-43.

Bousset L, Sprague SJ, Thrall PH, Barrett LB, 2018. Spatio-temporal connectivity and host resistance influence evolutionary and epidemiological dynamics of the canola pathogen Leptosphaeria maculans. Evolutionary Applications. In press.

Brachaczek A, Kaczmarek J, Jedryczka M, 2016. Monitoring blackleg (Leptosphaeria spp.) ascospore release timing and quantity enables optimal fungicide application to improved oilseed rape yield and seed quality. European Journal of Plant Pathology 145, 643-57.

Brun H, Chèvre AM, Fitt BDL et al., 2010. Quantitative resistance increases the durability of qualitative resistance to Leptosphaeria maculans in Brassica napus. New Phytologist 185, 285-99.

Cozijnsen AJ, Howlett BJ, 2003. Characterisation of the mating type locus of the plant pathogenic ascomycete Leptosphaeria maculans. Current Genetics 43, 351-7.

Daverdin G, Rouxel T, Gout L et al., 2012. Genome structure and reproductive behaviour influence the evolutionary potential of a fungal pathogen. PLoS Pathogens 8, e1003020.

Dawidziuk A, Kaczmarek J, Podlesna A, Kasprzyk I, Jedryczka M, 2012. Influence of meteorological parameters on Leptosphaeria maculans and L. biglobosa spore release in central and eastern Poland. Grana 51, 240-8.

De March G, Séguin-Swartz G, Petrie GA, 1986. Virulence and culture filtrate phytotoxicity in Leptosphaeria maculans: perspectives for in vitro selection. Canadian Journal of Plant Pathology $8,422-8$.

Delourme R, Chevre AM, Brun H et al., 2006. Major gene and polygenic resistance to Leptosphaeria maculans in oilseed rape (Brassica napus). European Journal of Plant Pathology 114, 41-52.

Delourme R, Bousset L, Ermel E et al., 2014. Quantitative resistance affects the speed of frequency increase but not the diversity of the virulence alleles overcoming a major resistance gene to Leptosphaeria maculans in oilseed rape. Infection, Genetics \& Evolution 27, 490-9.

Fisher KJ, Lang GI, 2016. Experimental evolution in fungi: an untapped resource. Fungal Genetics \& Biology 94, 88-94.

Gout L, Eckert M, Rouxel T, Balesdent MH, 2006. Genetic variability and distribution of mating-type alleles in field populations of Leptosphaeria maculans from France. Applied and Environmental Microbiology 72, 185-91.

Hall R, Chigogora JL, Phillips LG, 1996. Role of seedborne inoculum of Leptosphaeria maculans in development of blackleg on oilseed rape. Canadian Journal of Plant Pathology 18, 35-42.

Hammond KE, Lewis BG, Musa TM, 1985. A systemic pathway in the infection of oilseed rape plants by Leptosphaeria maculans. Plant Pathology 34, 557-65.

Huang YJ, Fitt BDL, Hall AM, 2003. Survival of A-group and B-group Leptosphaeria maculans (phoma stem canker) ascospores in air and mycelium on oilseed rape stem debris. Annals of Applied Biology 143, 359-69.

Huang YJ, Li ZQ, Evans N, Rouxel T, Fitt BDL, Balesdent MH, 2006. Fitness cost associated with loss of the AvrLm4 avirulence function in Leptosphaeria maculans (phoma stem canker of oilseed rape). European Journal of Plant Pathology 114, 77-89. 
Huang YJ, Pirie EJ, Evans N, Delourme R, King GJ, Fitt BDL, 2009. Quantitative resistance to symptomless growth of Leptosphaeria maculans (phoma stem canker) in Brassica napus (oilseed rape). Plant Pathology 58, 314-23.

Kolmer JA, 1993. Selection in a heterogeneous population of Puccinia recondita f. sp. tritici. Phytopathology 83, 909-14.

Lenth RV, 2016. Least-squares means: the R package 1smeans. Journal of Statistical Software 69, 1-33.

Lô-Pelzer E, Aubertot JN, David O, Jeuffroy MH, Bousset L, 2009. Relationship between severity of blackleg (Leptosphaeria maculans/ L. biglobosa species complex) and subsequent primary inoculum production on oilseed rape stubble. Plant Pathology 58, 61-70.

Lô-Pelzer E, Bousset L, Jeuffroy MH et al., 2010. SIPPOM-WOSR: a simulator for integrated pathogen population management of phoma stem canker on winter oilseed rape. I. Description of the model. Field Crops Research 118, 73-81.

Marcroft SJ, Sprague SJ, Pymer SJ, Salisbury PA, Howlett BJ, 2004. Crop isolation, not extended rotation length, reduces blackleg (Leptosphaeria maculans) severity of canola (Brassica napus) in southeastern Australia. Australian Journal of Experimental Agriculture 44, 601-6.

McCredden J, Cowley RB, Marcroft SJ, Van de Wouw AP, 2018. Changes in farming practices impact on spore release patterns of the blackleg pathogen, Leptosphaeria maculans. Crop \& Pasture Science $69,1-8$.

McDonald BA, Linde CC, 2002. Pathogen population genetics, evolutionary potential, and durable resistance. Annual Review of Phytopathology 40, 349-79.

Naseri B, Davidson JA, Scott ES, 2009. Maturation of pseudothecia and discharge of ascospores of Leptosphaeria maculans on oilseed rape stubble. European Journal of Plant Pathology 125, 52331.

R Core Team, 2013. R; a language and environment for statistical computing. R Foundation for Statistical Computing, Vienna, Austria. [http://www.R-project.org/]. Accessed 27 February 2018.

Rouxel T, Penaud A, Pinochet X et al., 2001. A 10-year survey of populations of Leptosphaeria maculans in France indicates a rapid adaptation towards the Rlm1 resistance gene of oilseed rape. European Journal of Plant Pathology 109, 871-81.

Rouxel T, Grandaubert J, Hane JK et al., 2011. Effector diversification within compartments of the Leptosphaeria maculans genome affected by repeat-induced point mutations. Nature Communications 2, 202.

Salam MU, Khangura RK, Diggle AJ, Barbetti MJ, 2003. Blackleg Sporacle: a model for predicting onset of pseudothecia maturity and seasonal ascospore showers in relation to blackleg of canola. Phytopathology 93, 1073-81.

Savage D, Barbetti MJ, MacLeod WJ, Salam MU, Renton M, 2013. Temporal patterns of ascospore release in Leptosphaeria maculans vary depending on geographic region and time of observation. Microbial Ecology 65, 584-92.

Shoemaker RA, Brun H, 2001. The teleomorph of the weakly aggressive segregate of Leptosphaeria maculans. Canadian Journal of Botany 79, 412-9.

Suffert F, Delestre G, Carpentier F et al., 2016. Fashionably late partners have more fruitful encounters: Impact of the timing of co-infection and pathogenicity on sexual reproduction in Zymoseptoria tritici. Fungal Genetics and Biology 92, 40-9.

Tollenaere C, Laine AL, 2013. Investigating the production of sexual resting structures in a plant pathogen reveals unexpected self-fertility and genotype-by-environment effects. Journal of Evolutionary Biology 26, 1716-26.

Toscano-Underwood C, Huang YJ, Fitt BDL, Hall AM, 2003. Effects of temperature on maturation of pseudothecia of Leptosphaeria maculans and L. biglobosa on oilseed rape stem debris. Plant Pathology 52, 726-36.

Travadon R, Marquer B, Ribulé A et al., 2009. Systemic progress of Leptosphaeria maculans from cotyledons to hypocotyl in oilseed rape: influence of the number of infection sites, of intraspecific competition and of host polygenic resistance. Plant Pathology 58, 461-9. 
Van de Wouw AP, Howlett BJ, Idnurm A, 2017. Changes in allele frequencies of avirulence genes in the blackleg fungus, Leptosphaeria maculans, over two decades in Australia. Crop \& Pasture Science 69, 20-9.

West JS, Kharbanda PD, Barbetti MJ, Fitt BDL, 2001. Epidemiology and management of Leptosphaeria maculans (phoma stem canker) on oilseed rape in Australia, Canada and Europe. Plant Pathology $50,10-27$.

Wherrett AD, Sivasithamparam K, Barbetti MJ, 2003. Chemical manipulation of Leptosphaeria maculans (blackleg disease) pseudothecial development and timing of ascospore discharge from canola (Brassica napus) residues. Australian Journal of Agricultural Research 54, 837-48.

Winter M, Koopmann B, 2016. Race spectra of Leptosphaeria maculans, the causal agent of blackleg disease of oilseed rape, in different geographic regions in northern Germany. European Journal of Plant Pathology 145, SI 629-41.

Zhang X, Peng P, Kutcher R, Balesdent MH, Delourme R, Fernando DWG, 2016. Breakdown of Rlm3 resistance in the Brassica napus-Leptosphaeria maculans pathosystem in western Canada. European Journal of Plant Pathology 145, 659-74. 